\title{
Dexmedetomidine during suprazygomatic maxillary nerve block for pediatric cleft palate repair, randomized double-blind controlled study
}

\author{
Mohamed F. Mostafa ${ }^{1}$, Fatma A. Abdel Aal ${ }^{1}$, Ibrahim Hassan Ali ${ }^{1}$, Ahmed K. Ibrahim², and Ragaa Herdan ${ }^{1}$
}

'Department of Anesthesia and Intensive Care, Faculty of Medicine, Assiut University, Assiut, Egypt

2Department of Public Health, Faculty of Medicine, Assiut University, Assiut, Egypt

Received July 26, 2019

Revised December 3, 2019

Accepted December 3, 2019

\section{Correspondence}

Mohamed F. Mostafa

Department of Anesthesia and Intensive Care, Assiut University Hospital, Faculty

of Medicine, Assiut University, Assiut

71515, Egypt

Tel: +20-1001123062

Fax: +20-88-2333327

E-mail:mo7_fathy@yahoo.com
Background: For children with cleft palates, surgeries at a young age are necessary to reduce feeding or phonation difficulties and reduce complications, especially respiratory tract infections and frequent sinusitis. We hypothesized that dexmedetomidine might prolong the postoperative analgesic duration when added to bupivacaine during nerve blocks.

Methods: Eighty patients of 1-5 years old were arbitrarily assigned to two equal groups (forty patients each) to receive bilateral suprazygomatic maxillary nerve blocks. Group A received bilateral $0.2 \mathrm{~mL} / \mathrm{kg}$ bupivacaine $(0.125 \%$; maximum volume $4 \mathrm{~mL} /$ side). Group B received bilateral $0.2 \mathrm{~mL} / \mathrm{kg}$ bupivacaine $(0.125 \%)+0.5$ $\mu \mathrm{g} / \mathrm{kg}$ dexmedetomidine (maximum volume $4 \mathrm{~mL} / \mathrm{side}$ ).

Results: The modified children's hospital of Eastern Ontario pain scale score was significantly lower in group B children after 8 hours of follow-up postoperatively $(P<$ $0.001)$. Mean values of heart rate and blood pressure were significantly different between the groups, with lower mean values in group B $(P<0.001)$. Median time to the first analgesic demand in group A children was 10 hours (range 8-12 hr), and no patients needed analgesia in group $B$. The sedation score assessment was higher in children given dexmedetomidine $(P=0.03)$ during the first postoperative 30 minutes. Better parent satisfaction scores (5-point Likert scale) were recorded in group $B$ and without serious adverse effects.

Conclusions: Addition of dexmedetomidine $0.5 \mu \mathrm{g} / \mathrm{kg}$ to bupivacaine $0.125 \%$ has accentuated the analgesic efficacy of bilateral suprazygomatic maxillary nerve block in children undergoing primary cleft palate repair with less postoperative supplemental analgesia or untoward effects.

Key Words: Analgesia; Bupivacaine; Child; Cleft Palate; Dexmedetomidine; Maxillary Nerve; Nerve Block; Pain, Postoperative

\section{INTRODUCTION}

Cleft palate (CP) is a widespread congenital disfigurement with a high occurrence rate [1]. Early surgical corrections are important to reduce any feeding or phonation diffi- culties and reduce respiratory tract complications [2]. CP repair is painful and necessitates high doses of opioids for analgesia with a higher risk of postoperative airway obstruction or respiratory depression. Therefore, continuous monitoring is necessary at least during the first postopera- (c) This is an open-access article distributed under the terms of the Creative Commons Attribution Non-Commercial License (http://creativecommons.org/licenses/by-nc/4.0/), which permits unrestricted non-commercial use, distribution, and reproduction in any medium, provided the original work is properly cited.

(c) The Korean Pain Society, 2020
Author contributions: Mohamed F. Mostafa: Writing/manuscript preparation; Fatma A. Abdel Aal: Supervision; Ibrahim Hassan Ali: Investigation; Ahmed K. Ibrahim: Data curation; Ragaa Herdan: Methodology. 
tive 24 hours [3].

Widespread, pediatric regional analgesia forms a part of the anesthetic art. However, pediatric regional analgesia is still limited in some literature because analgesia using opiates is considered the best, even though it has potential risks. Usually investigators have given analgesics to children after the end of surgery [4]. Regional anesthesia may be associated with some risks that are similar to that of opiates [5].

Maxillary nerve blocks (MNBs) have elicited many approaches. The infrazygomatic route is useful for trigeminal neuralgia in adults, but presents several risks, as orbit or skull penetration and accidental maxillary artery puncture may occur. The palatine nerve block may be beneficial for analgesia after $\mathrm{CP}$ repair, but requires the identification of the first molars, which are absent in infants [6]. The suprazygomatic technique for MNB has fewer complications [7]. It is simple, reliable and an almost risk-free approach for children with effective and prolonged analgesia [8]. Anesthesiologists can reach the maxillary nerve after its emergence from the foramen rotundum, within the pterygopalatine fossa before it branches to innervate the palate [9].

Many adjuvants have been combined with local anesthetics (LAs) to boost the nerve block characteristics i.e. alpha-2 agonists, corticosteroids, epinephrine, bicarbonate, and opioids. Dexmedetomidine is a highly selective alpha-2 adrenergic agonist with both analgesic and sedative effects. Perineural injection of dexmedetomidine prolonged the time span of both sensory and motor blocks when added to LAs during the brachial plexus block (BPB) [10]. Many investigators reported faster onset and longer duration of the sensory block when using dexmedetomidine for the greater palatine, axillary brachial, and ulnar nerve blocks [11].

From this background this study hypothesized that dexmedetomidine would prolong postoperative analgesia when added to bupivacaine during nerve blocks. The primary objective of the study was to evaluate the analgesic effect of adding dexmedetomidine to bupivacaine during bilateral suprazygomatic maxillary nerve blocks (SMBs) in children scheduled for $\mathrm{CP}$ repair under general anesthesia (GA) by measuring the modified children's hospital of Eastern Ontario pain scale (CHEOPS). Secondary objectives were to study the safety of adding dexmedetomidine to SMB and reporting any possible adverse effects related to the drug or the procedure.

\section{MATERIALS AND METHODS}

\section{Eligibility of the study}

This randomized controlled double-blind study was performed in Assiut University Hospitals after approval from Faculty of Medicine, Assiut University, Institutional Ethics Committee (ID: IRB17100118). It was recorded in the Clinical Trials Registration (ClinicalTrials.gov ID: NCT03412474). Patients' guardians were provided with complete information about the techniques of anesthesia and analgesia, and informed written consent was obtained from them. They could participate or withdraw at any time without affecting the medical service to their children. All gathered data were considered private and used for the scientific purposes only.

Sample size calculation was carried out using G*Power 3 software [12]. A total calculated minimal sample of 72 patients was needed to reveal an effect size of $50 \%$ reduction in the postoperative pain scores based on previous literature [3-5], with an error probability of 0.05 and $90 \%$ power on a two-tailed test. This was raised to include 80 to compensate for dropouts; 40 in each group.

\section{Inclusion criteria}

The study included children aged 1-5 years, of both sexes, ASA (I-II), and scheduled for primary CP (grade 1 or 2 ) surgeries under GA.

\section{Exclusion criteria}

Caregivers' refusal, a history of developmental delay or mental retardation, hypersensitivity to LAs, bleeding diathesis, skin lesions or wounds at the puncture site of the proposed block, and children with any co-morbidities.

\section{Randomization}

Patients were randomly assigned to two equal groups (of 40 children each). A computer-generated program of random numbers was used to allocate participation for each group. Group A patients received SMB using $0.2 \mathrm{~mL} / \mathrm{kg}$ of bupivacaine $(0.125 \%)$ on each side (with maximum volume of $4 \mathrm{~mL}$ ). Group B patients received SMB using $0.2 \mathrm{~mL} / \mathrm{kg}$ of bupivacaine $(0.125 \%)+0.5 \mu \mathrm{g} / \mathrm{kg}$ of dexmedetomidine on each side (with a maximum volume of $4 \mathrm{~mL}$ ). Neither the doctors (investigators) nor the patients' guardians or even the children themselves were aware of the group allocation and the drug received. One anesthesiologist not involved in the block implementation or the data collection, prepared all the study solutions. Another investigator 
(blinded to the study solution preparation and group allocation) was responsible for performing the MNB. While a third, blinded to the previous protocol, was responsible only for data collection.

\section{Outcomes}

The primary outcome was the postoperative pain (measured by the modified CHEOPS for postoperative pain assessment in children). Secondary outcomes included hemodynamic variables, time to first postoperative rescue analgesia, sedation score, parents' satisfaction score, and any possible complications.

\section{Study procedure}

One day before surgery, children were submitted to preanesthetic screening including a detailed history, global general, and physical check. The Mallampati score was used for airway assessment in all children to diagnose cases with expected difficult intubation. Patients fasted from solid foods for 6-8 hours, though only 2 hours for clear fluids. Emergency resuscitation equipment was available during the whole period of the study, including airway instruments and drugs for pediatric advanced life support.

\section{Intraoperative conduct}

The anesthetic procedure was standardized, and the same surgical team performed all surgeries. All investigators were unaware of the patient's destination and the study medications. Standardized GA was applied to all children using 6\%-8\% sevoflurane, using a face mask of suitable size. Intraoperative monitoring included the electrocardiogram, pulse oximetry $\left(\mathrm{SpO}_{2}\right)$, non-invasive mean arterial blood pressure (MAP), end-tidal carbon dioxide $\left(\mathrm{EtCO}_{2}\right)$, and temperature probe. An intravenous (IV) cannula 22 $G$ was inserted after induction of GA and an IV infusion of $0.9 \% \mathrm{NaCl}$ at the calculated rate and volume. Then all patients received IV fentanyl $1 \mu \mathrm{g} / \mathrm{kg}$, propofol $2 \mathrm{mg} / \mathrm{kg}$ and an endotracheal tube (ETT) of appropriate size was inserted and secured. Assisted ventilation using an Ayre's T-piece (Anesthesia Service and Equipment, Atlanta, GA) to maintain $\mathrm{EtCO}_{2}$ at $35 \pm 5 \mathrm{mmHg}$. GA was maintained with $2 \%-3 \%$ sevoflurane sevoflurane. Dexamethasone 0.5 $\mathrm{mg} / \mathrm{kg}$ (maximum $8 \mathrm{mg}$ ) and the proper antibiotic were administered intravenously.

Bilateral SMB was carried out before starting surgeries in all anesthetized children while the patients were in the supine position with the head in a neutral position. After complete aseptic skin preparation, the needle puncture site was at the junction of the frontal bone with the up- per edge of the zygomatic arch (frontozygomatic angle). A long $(50 \mathrm{~mm})$ and thin needle $(25 \mathrm{G})$ was used to reach the pterygopalatine fossa (35-45 $\mathrm{mm}$ distance from the skin puncture site). The blinded study solution was injected on each side after a negative blood aspiration test [3]. Any immediate complications related to SMB were carefully monitored i.e. systemic toxicity related to LAs, bleeding at the puncture site, pupil alteration, or ocular lesion (Fig. 1).

Before inducing GA and just before performing the SMB; the baseline heart rate (HR), $\mathrm{MAP}, \mathrm{SpO}_{2}$, and $\mathrm{EtCO}_{2}$ readings were observed and then every 10 minutes after the block until the end of surgery. The surgical incision was started 20 minutes after the SMB. In case of inadequate analgesia after the surgical incision (diagnosed by a $20 \%$ increase of HR and/or MAP above their baseline values), IV fentanyl $1 \mu \mathrm{g} / \mathrm{kg}$ was given and the child was ruled out from participating in the study. An intraoperative decrease in HR and/or MAP by $20 \%$ from the baseline values were diagnosed and treated promptly. After completion of the surgical procedure, ETT extubation was done after ensuring adequate endotracheal and oropharyngeal suction and the patient was transferred to the post-anesthesia care unit (PACU).

In the PACU: $\mathrm{HR}, \mathrm{MAP}, \mathrm{SpO}_{2}$, and the modified CHEOPS [13] were documented directly after admission to the PACU then at $1,4,8,12,18$, and 24 hours postoperatively. An investigator who was blinded to the study protocol collected the PACU monitoring data. Postoperative pain was measured using the modified CHEOPS where the minimum score of zero (no pain) and the maximum score of 12 (the most severe pain). Children with the modified CHEOPS $\geq$ 5 were given supplemental analgesia with IV paracetamol 15 mg/kg (Perfalgan, 1,000 mg; UPSA Laboratories, Rueil-

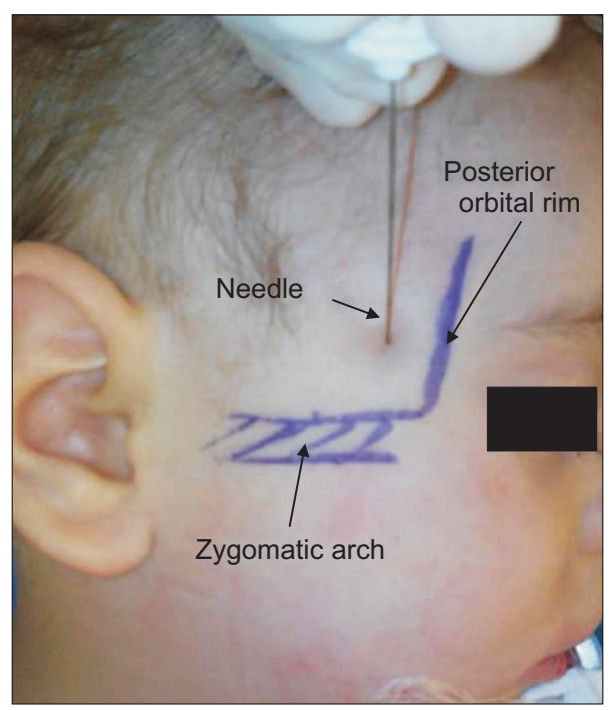

Fig. 1. Suprazygomatic maxillary nerve block landmarks. 
Malmaison, France). Pain scores were recorded 15-20 minutes following the administration of this supplemental analgesia to assess pain relief. The number of children that required postoperative rescue analgesics, the first time to rescue analgesia, and the total amount of rescue analgesia consumed within 24 hours postoperatively were recorded.

Postoperative sedation was assessed using a sedation score [14] which ranged from fully awake to the unarousable child. Other complications related to the SMB blocks were recorded as hematomas, restricted mouth opening, vision, sensory or motor deficit, and eating disorder.

The five-point Likert scale [15] was applied to evaluate the parents' satisfaction regarding the whole procedure at the end of postoperative 24 hours. It ranged from very satisfied to very dissatisfied parents. When all children were well and eating properly, they were sent home.

\section{Statistical analysis}

Data were verified and analyzed using IBM SPSS ver. 23.0 (IBM Corp., Armonk, NY). Descriptive data were presented as mean \pm standard deviation, numbers, or percentages. Continuous data were compared between the groups using the independent Student's $t$-test. For repeated measures, repeated measure ANOVA was used to compare the mean changes over time in each group. Categorical variables (age, sex, and parents' satisfaction scores) were analyzed using the chi-square test. For repeated measures, chisquare test for trend was used to compare the proportion changes over time in each group. A $P$ value of less than 0.05 was considered to indicate statistical significance.

\section{RESULTS}

This clinical study was conducted on 80 children scheduled for CP repair under GA and bilateral SMB for postoperative analgesia. A flow diagram of the study is shown in Fig. 2. Both groups were comparable regarding demo-

Table 1. Demographic Data and Clinical Characteristics of Both Groups

\begin{tabular}{lccc}
\hline \multicolumn{1}{c}{ Characteristic } & $\begin{array}{c}\text { Group A } \\
(\mathrm{n}=40)\end{array}$ & $\begin{array}{c}\text { Group B } \\
(\mathrm{n}=40)\end{array}$ & $P$ value* \\
\hline Age (yr) & $1.6 \pm 0.6$ & $1.7 \pm 0.7$ & $0.98^{\mathrm{a}}$ \\
Weight (kg) & $10.9 \pm 1.4$ & $11.3 \pm 2.1$ & $0.07^{\mathrm{a}}$ \\
Sex & & & $0.30^{\mathrm{b}}$ \\
$\quad$ Male & $25(62.5)$ & $22(55.0)$ & \\
$\quad$ Female & $15(37.5)$ & $18(45.0)$ & \\
Duration of anesthesia (min) & $88.98 \pm 3.9$ & $91.34 \pm 2.1$ & $0.45^{\mathrm{a}}$ \\
Duration of surgery (min) & $77.34 \pm 10.3$ & $79.23 \pm 12.3$ & $0.30^{\mathrm{a}}$ \\
Time of recovery from GA (min) & $12.50 \pm 2.4$ & $14.00 \pm 3.3$ & $0.59^{\mathrm{a}}$ \\
\hline
\end{tabular}

Values are presented as mean \pm standard deviation or number (\%). Group A received bilateral $0.2 \mathrm{~mL} / \mathrm{kg}$ bupivacaine $(0.125 \%$; maximum volume $4 \mathrm{~mL} /$ side). Group B received bilateral $0.2 \mathrm{~mL} / \mathrm{kg}$ bupivacaine $(0.125 \%)+0.5 \mu \mathrm{g} / \mathrm{kg}$ dexmedetomidine (maximum volume $4 \mathrm{~mL} /$ side) . $\mathrm{GA}$ : general anesthesia.

$* P$ value $<0.05$ was considered significant.

andependent t-test was used to compare the mean difference between groups. ${ }^{b} \chi^{2}$ test was used to compare the proportion difference between groups.

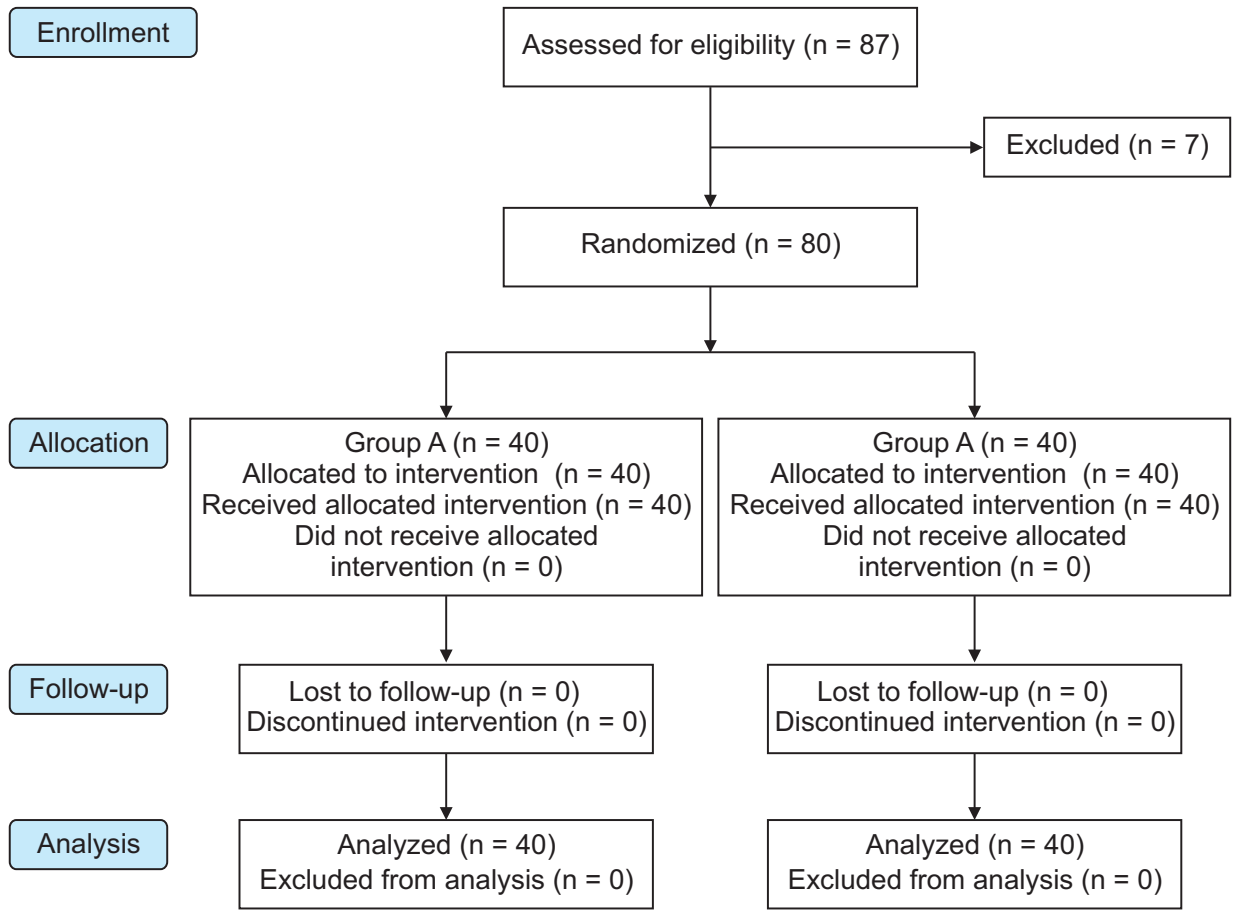

Fig. 2. CONSORT flow diagram of the two studied groups. Group A received bilateral $0.2 \mathrm{~mL} / \mathrm{kg}$ bupivacaine $(0.125 \%$; maximum volume $4 \mathrm{~mL} /$ side). Group B received bilateral $0.2 \mathrm{~mL} / \mathrm{kg}$ bupivacaine $(0.125 \%)+0.5 \mu \mathrm{g} / \mathrm{kg}$ dexmedetomidine (maximum volume $4 \mathrm{~mL} /$ side). 
graphic data and clinical characteristics (age, sex, weight, duration of anesthesia, duration of surgery, and time of recovery) (Table 1). There was no significant difference between these groups in regards to the baseline data of HR and MAP. The subsequent readings of HR and MAP showed that there was a significant difference between the

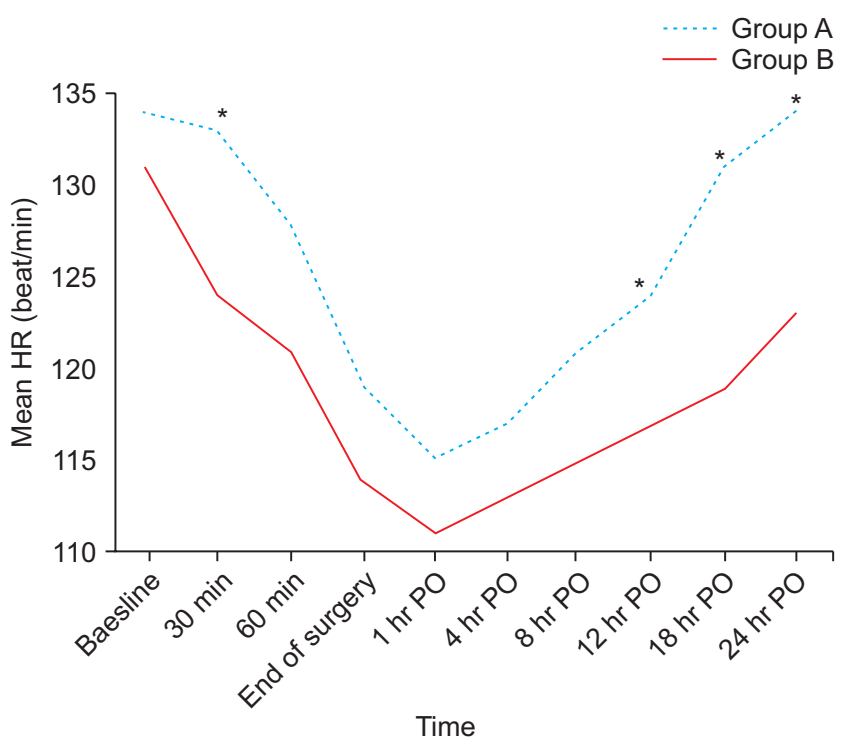

Fig. 3. Changes in heart rate (HR) in the two studied groups. Group A received bilateral $0.2 \mathrm{~mL} / \mathrm{kg}$ bupivacaine $(0.125 \%$; maximum volume 4 $\mathrm{mL} /$ side). Group B received bilateral $0.2 \mathrm{~mL} / \mathrm{kg}$ bupivacaine $(0.125 \%)+$ $0.5 \mu \mathrm{g} / \mathrm{kg}$ dexmedetomidine (maximum volume $4 \mathrm{~mL} /$ side). PO: postoperative. $* P<0.05$

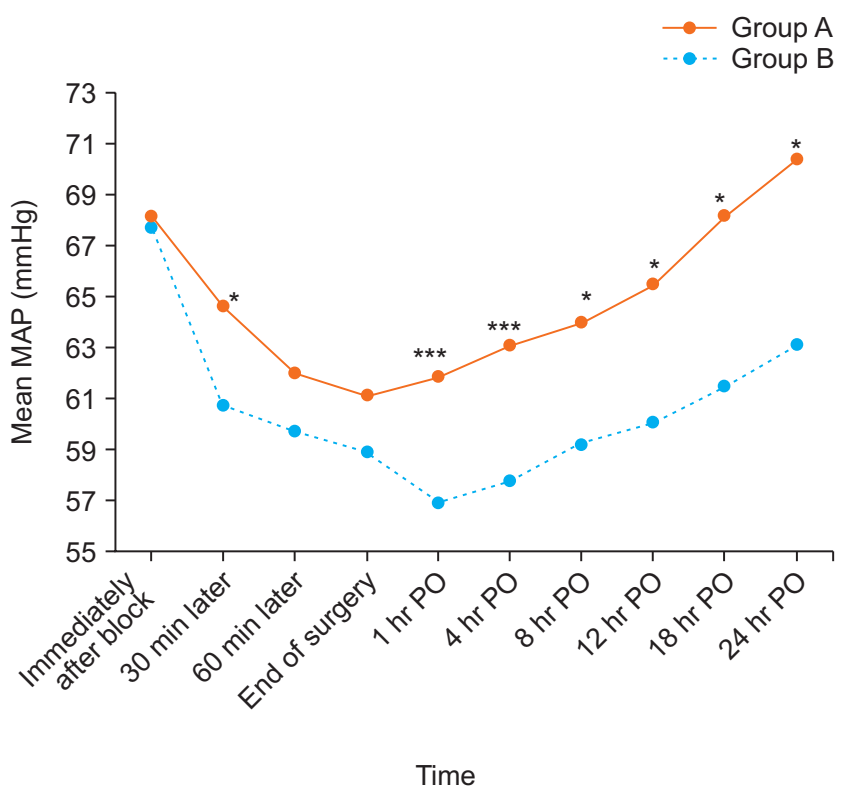

Fig. 4. Changes in mean arterial blood pressure (MAP) in the two studied groups. Group A received bilateral $0.2 \mathrm{~mL} / \mathrm{kg}$ bupivacaine $(0.125 \%$; maximum volume $4 \mathrm{~mL} / \mathrm{side}$ ). Group B received bilateral $0.2 \mathrm{~mL} / \mathrm{kg}$ bupivacaine $(0.125 \%)+0.5 \mu \mathrm{g} / \mathrm{kg}$ dexmedetomidine (maximum volume $4 \mathrm{~mL} /$ side). PO: postoperative. $* P<0.05 . * * * P<0.001$. groups with lower mean values in the group $B$ patients in comparison to those of group A with $P<0.001$ (Figs. 3, 4).

The modified CHEOPS score was statistically significantly lower in the group B children when compared to those of group A after 8 hours of postoperative follow-up. Regarding the modified CHEOPS score in group A, the mean values significantly increased with time especially after 8 hours postoperatively in comparison to the mean values measured on PACU admission. However, the mean values of the modified CHEOPS scores measured in group B did not significantly change at different postoperative follow-up times as compared to the mean values measured on PACU admission (Table 2).

During periods of postoperative follow-up, no child in group B required analgesia within the first 24 hours postoperatively (the duration of analgesia was $\geq 24 \mathrm{hr}$, and the total amount of rescue analgesic consumption was $0.0 \pm$ $0.0 \mathrm{mg}$ ). While all the children in group A needed analgesia after 8 hours postoperatively (the median time to the first analgesic request was $10 \mathrm{hr}$ with a range of 8-12 hr). Regarding the total amount of rescue analgesic consumption in group A, children received mean values of IV paracetamol $(237.78 \pm 129.88 \mathrm{mg})$ till the end of the first postoperative 24 hours with a range of 2-3 times administered $/ 24 \mathrm{hr}$.

It was noticed that the sedation score was significantly higher in the children receiving dexmedetomidine (group B) in comparison to the children of group A with $P=0.003$ in the first postoperative hour. Patients of both groups were fully conscious after 1 hour postoperatively, and started good oral feeding within 2 hours postoperatively

Table 2. Differences in Postoperative Analgesia; Measured by Modified CHEOPS

\begin{tabular}{lccr}
\hline \multicolumn{1}{c}{ Time } & Group A $(\mathrm{n}=40)$ & Group B $(\mathrm{n}=40)$ & $P$ value $^{\mathrm{a}, *}$ \\
\hline On PACU admission & $1.10 \pm 0.03$ & $1.00 \pm 0.05$ & 0.132 \\
$1 \mathrm{hr}$ PO & $1.30 \pm 0.05$ & $1.00 \pm 0.07$ & 0.121 \\
$4 \mathrm{hr}$ PO & $2.00 \pm 0.04$ & $1.92 \pm 0.05$ & 0.198 \\
$8 \mathrm{hr}$ PO & $5.13 \pm 1.1$ & $1.95 \pm 0.03$ & $<0.001$ \\
$12 \mathrm{hr}$ PO & $4.18 \pm 0.01$ & $2.05 \pm 0.02$ & 0.002 \\
$18 \mathrm{hr}$ PO & $2.10 \pm 0.02$ & $1.00 \pm 0.02$ & 0.021 \\
$24 \mathrm{hr}$ PO & $1.33 \pm 0.04$ & $0.80 \pm 0.02$ & 0.004 \\
v value $^{\mathrm{b}, *}$ & $<0.001$ & 0.192 & $0.024^{\mathrm{c}}$ \\
\hline
\end{tabular}

Values are presented as mean \pm standard deviation. Group A received bilateral $0.2 \mathrm{~mL} / \mathrm{kg}$ bupivacaine (0.125\%; maximum volume $4 \mathrm{~mL} / \mathrm{side})$. Group B received bilateral $0.2 \mathrm{~mL} / \mathrm{kg}$ bupivacaine $(0.125 \%)+0.5 \mu \mathrm{g} / \mathrm{kg}$ dexmedetomidine (maximum volume $4 \mathrm{~mL} / \mathrm{side}$ ).

CHEOPS: children's hospital of Eastern Ontario pain scale, PACU: postanesthesia care unit, PO: postoperative.

* $P$ value $<0.05$ was considered significant.

${ }^{a}$ Independent $t$-test for the mean difference between both groups. ${ }^{\mathrm{b}} \mathrm{Two}$ way repeated measures ANOVA for data of the same group at different times. ${ }^{\circ}$ Time* group interaction. 
Table 3. Postoperative Sedation Score in the Two Studied Groups

\begin{tabular}{cccc}
\hline Sedation score & Group A $(n=40)$ & Group B $(n=40)$ & $P$ value $^{a_{*} *}$ \\
\hline 1 & $31(77.5)$ & $24(60.0)$ & 0.003 \\
2 & $8(20.0)$ & $11(27.5)$ & \\
3 & $1(2.5)$ & $3(7.5)$ & \\
4 & $0(0.0)$ & $2(5.0)$ & \\
5 & $0(0.0)$ & $0(0.0)$ & \\
\hline
\end{tabular}

Values are presented as number (\%). Group A received bilateral 0.2 $\mathrm{mL} / \mathrm{kg}$ bupivacaine (0.125\%; maximum volume $4 \mathrm{~mL} /$ side). Group B received bilateral $0.2 \mathrm{~mL} / \mathrm{kg}$ bupivacaine $(0.125 \%)+0.5 \mu \mathrm{g} / \mathrm{kg}$ dexmedetomidine (maximum volume $4 \mathrm{~mL} /$ side).

${ }^{*} P$ value $<0.05$ was considered significant.

${ }^{a} \chi^{2}$ test for trend was used to compare the proportion difference between groups.

(Table 3).

Higher parental satisfaction scores (5-point Likert scale; $P=0.001$ ) were recorded in group B children compared with group $A$ at the end of 24 hours postoperatively. Parents of the children in group B were recorded as $57.5 \%$ very satisfied, $40.0 \%$ satisfied and $2.5 \%$ neutral. While parents for children in the other group showed that only $2.5 \%$ of them were satisfied, $87.5 \%$ were neutral and $10.0 \%$ of them were dissatisfied (Table 4).

The present study showed that there were no serious adverse effects observed in either group, either intraoperatively or postoperatively.

\section{DISCUSSION}

Cleft lips or palates are widespread pediatric craniofacial anomalies with an incidence of 1:800. CP alone represents 1:2,000 of all live births [16]. A successful outcome after CP repair depends on the patient's age, co-morbidities, anesthetic experience and postoperative follow-up [17]. Anesthesia for $\mathrm{CP}$ repair poses a higher risk with GA and airway problems. A higher incidence of perioperative respiratory complications occurs if associated with common cold [18].

Regional anesthesia in children has many advantages especially hemodynamic stability, the absence of respiratory depression, less postoperative need for ventilatory support, an earlier return of bowel function, and early subsequent feeding, in addition to the economic benefits of a shorter hospital stay [4]. There is a growing awareness in recent years of the need for children's complete wellbeing in postoperative periods, and not only being pain free. Sedation and other adverse events related to opioids do not help in achieving this goal [19]. Postoperative pain may extend beyond the nerve block resolution duration. Increasing the volume (dose) LAs may prolong the duration of analgesia but with a higher incidence of systemic
Table 4. Parents' Satisfaction Based on 5-Likert Scale in Both Groups

\begin{tabular}{lccc}
\hline \multicolumn{1}{c}{ Scale } & Group A $(n=40)$ & Group B $(n=40)$ & $P$ value $^{\mathrm{a}, *}$ \\
\hline Very satisfied & $0(0)$ & $23(57.5)$ & 0.001 \\
Satisfied & $1(2.5)$ & $16(40.0)$ & \\
Neutral & $35(87.5)$ & $1(2.5)$ & \\
Dissatisfied & $4(10.0)$ & $0(0.0)$ & \\
Very dissatisfied & $0(0.0)$ & $0(0.0)$ & \\
\hline
\end{tabular}

Values are presented as number (\%). Group A received bilateral 0.2 $\mathrm{mL} / \mathrm{kg}$ bupivacaine $(0.125 \%$; maximum volume $4 \mathrm{~mL} /$ side). Group B received bilateral $0.2 \mathrm{~mL} / \mathrm{kg}$ bupivacaine $(0.125 \%)+0.5 \mu \mathrm{g} / \mathrm{kg}$ dexmedetomidine (maximum volume $4 \mathrm{~mL} / \mathrm{side}$ ).

${ }^{*} P$ value $<0.05$ was considered significant.

${ }^{a} \chi^{2}$ test for trend was used to compare the proportion difference between groups.

toxicity. Use of dexmedetomidine as a perineural adjuvant can prolong both sensory and motor block durations [20].

The present study investigated the analgesic effect of adding dexmedetomidine to bupivacaine in bilateral SMB for children who underwent primary CP repair under GA. We demonstrated no statistically significant differences in the mean values of HR and MAP at baseline readings immediately after the block between the two groups. This may be due to the application of mouth spacers which resulted in painful stress on the temporomandibular joints, some areas being unblocked by SMB, and palatal lidocaine with epinephrine infiltration which is considered a confounding factor for hemodynamic changes in cases of resorption. Adding dexmedetomidine to bupivacaine significantly decreased the hemodynamics in group B during all investigated periods of anesthesia as compared with baseline values immediately after the block. Group $B$ patients showed a slightly greater decrease in the mean hemodynamics values than group $A$ at most investigated times of anesthesia.

Although dexmedetomidine can cause dose-dependent side effects such as bradycardia and hypotension [21], we did not record any adverse effects with this dose of $0.5 \mu \mathrm{g} /$ $\mathrm{kg}$ dexmedetomidine when added to the SMB. Some investigators noticed that an addition of dexmedetomidine $0.5 \mu \mathrm{g} / \mathrm{kg}$ to bupivacaine bilaterally in the transversus abdominis plane block decreased the HR 60 minutes from the induction time and continued for the first 4 hours postoperatively $(P<0.001)$ in patients that underwent abdominal hysterectomy [22].

Administering perineural dexmedetomidine to short acting LAs during the BPB prolonged the sensory block duration by at least $57 \%$ and the motor block duration by at least $26 \%$. Perineural dexmedetomidine reduced the postoperative rest pain scores at 24 hours, and reduced the total amount of postoperative analgesic consumption [23]. A recent study showed that adding dexmedetomidine to 
the axillary BPB prolonged the duration of both sensory and motor nerve blocks without any major side effects [24]. Some investigators demonstrated that adding dexamethasone or dexmedetomidine to LAs during axillary BPBs extended the sensory block duration with no significant differences regarding the onset time of sensory block or postoperative complications [10].

Even after administration of rescue analgesia in group A in our study, the pain score values were still lower in group B, while no rescue analgesia was needed. Postoperative pain was measured using the modified CHEOPS. We noticed that the CHEOPS score was significantly lower in children who had received dexmedetomidine with bupivacaine in comparison to the children who received bupivacaine alone after 8 hours of follow-up postoperatively. All children from group A required analgesia after 8 hours postoperatively. This is probably due to the end of the analgesic effect of the block in those children. The median time to the first analgesic requirement was 10 hours with a range between 8 and 12 hours.

Jonnavithula et al. [25] agreed with our results. They studied the efficacy of the palatal block i.e. blocking of nasopalatine, as well as the greater and lesser palatine nerves in children undergoing palatoplasty. The control group NB received no block, group $S$ received $0.5 \mathrm{~mL}$ of normal saline and group B received $0.5 \mathrm{~mL}$ of bupivacaine $0.25 \%$ for the palatal block. They assessed postoperative pain using the face, legs, activity, cry, consolability (FLACC) pain scale. The FLACC scores of group NB were significantly higher than those of groups $S$ and $B$. The number of rescue analgesic requirements was significantly higher in group NB compared to group $S$ and group B.

Chiono et al. [3] investigated 60 children scheduled for bilateral SMB with GA using normal saline (the saline group) or ropivacaine (the ropi group). They reported no statistically significant difference in the children's and infants' postoperative pain scale (CHIPPS) scores in the first 4 hours postoperatively. Sola et al. [26] scheduled 50 children for CP repair surgeries with ultrasound-guided SMB. Nalbuphine $(0.2 \mathrm{mg} / \mathrm{kg})$ IV was given as the rescue analgesia up to 4 times/day. Sixteen (64\%) patients required nalbuphine (one bolus within the first $48 \mathrm{hr}$, mainly in the recovery room) and five (20\%) patients required nalbuphine through continuous infusion. The study by Mesnil et al. [8] enrolled 33 children for palatoplasty. A bilateral SMB was performed using ropivacaine $0.2 \%(0.15 \mathrm{~mL} / \mathrm{kg})$. Postoperative rescue analgesia and adverse effects were recorded in the postoperative 48 hours. No patients from those receiving an SMB needed morphine postoperatively and only six patients (18\%) required IV nalbuphine.

However, our results were inconsistent with the randomized trial by Kamath et al. [27], who assessed pain in
50 children using the CHEOPS. Group A received IV pethidine $1 \mathrm{mg} / \mathrm{kg}$ and group B received bilateral greater palatine nerve blocks with bupivacaine $0.25 \%$. No statistically significant difference regarding pain scores was observed between the two groups except immediately postoperative, where $44 \%$ of group A patients expressed a pain score > 8 ; whereas, in the group B, it was only $12 \%$. The pain scores were comparable to our results until 10 hours postoperatively. A possible explanation for this comparison to our work is that Kamath et al. [27] used pethidine $0.5 \mathrm{mg} / \mathrm{kg}$ as rescue analgesia while we used IV paracetamol $15 \mathrm{mg} / \mathrm{kg}$.

Obayah et al. [28] reported the effects of adding dexmedetomidine to bupivacaine during greater palatine nerve blocks in children scheduled for CP repair. They found that the FLACC pain scale scores were significantly higher in the bupivacaine (B) group than that of the bupivacaine with dexmedetomidine (BD) group. The time to the first rescue analgesic request was significantly longer in the group BD children. They concluded that the combination of dexmedetomidine and bupivacaine increased the analgesic duration after $\mathrm{CP}$ repair by $50 \%$ with no clinically relevant adverse effects. Mostafa et al. [29] reported that the bilateral SMB is effective and safe for pain relief in children scheduled for primary $\mathrm{CP}$ repair surgeries with no severe side effects. They found that levobupivacaine is as effective as bupivacaine for SMB. We reported in the present study that adding adjuvants to LAs significantly increases the duration of postoperative analgesia.

In the present study, we noticed that the sedation score was significantly higher in those children receiving bupivacaine with dexmedetomidine in comparison to those children receiving bupivacaine alone in the first postoperative hour only $(P=0.03)$. This is in agreement with Ahmed et al. [30] who found that adding dexmedetomidine $20 \mu \mathrm{g}$ to bupivacaine $0.5 \%$ during the peribulbar block in patients receiving vitreoretinal surgeries increased the level of sedation significantly $(P<0.05)$. In addition, Anand et al. [31] reported that when dexmedetomidine $2 \mu \mathrm{g} / \mathrm{kg}$ was administered caudally, it prevented agitation and significantly increased the mean sedation score in patients who had undergone lower abdominal surgeries under GA.

A meta-analysis on the role of dexmedetomidine during neuraxial blocks concluded that it is a favorable adjuvant to LAs in providing prolonged anesthesia and analgesia. It decreases the need for postoperative rescue analgesics, but bradycardia often occurs [32]. Many studies on interscalene, supraclavicular, cervical plexus, and ulnar nerve blocks concluded that the use of dexmedetomidine increased the quality and duration of postoperative analgesia when added to commonly used LAs like bupivacaine and ropivacaine [33]. Dexmedetomidine can cause side effects such as bradycardia and hypotension with an in- 
creased dose [34].

There are some limitations in this study. We did not include a GA group (as a control group) receiving sevoflurane alone to assess if adding regional LA to GA would result in similar or better findings. However, we performed this comparison in a previous study. Another limitation is that real-time ultrasonography could not be used with the SMB to decrease the possible complications. However, we recorded no serious adverse effects due to our technique or the drugs used. Finally, even though the amount of bupivacaine (in mg) was not changed in either group as calculated based on body weight, it would be better to make the total volume equal by adding normal saline in the control group.

In conclusion, the addition of dexmedetomidine $0.5 \mu \mathrm{g} /$ $\mathrm{kg}$ to bupivacaine $0.125 \%$ has accentuated the analgesic efficacy of bilateral SMB in children undergoing primary $\mathrm{CP}$ repair with less postoperative supplemental analgesia or untoward effects.

\section{ACKNOWLEDGMENTS}

The authors would like to express their extreme gratitude to "Operation Smile Egypt", who supported this work.

\section{CONFLICT OF INTEREST}

No potential conflict of interest relevant to this article was reported.

\section{FUNDING}

No Funding to declare.

\section{ORCID}

Mohamed F. Mostafa, https://orcid.org/0000-0002-3500-7339

Fatma A. Abdel Aal, https://orcid.org/0000-0002-6964-0319

Ibrahim Hassan Ali, https://orcid.org/0000-0002-8378-6103

Ahmed K. Ibrahim, https://orcid.org/0000-0001-7038-217X

Ragaa Herdan, https://orcid.org/0000-0001-9782-5284

\section{REFERENCES}

1. Liau JY, Sadove AM, van Aalst JA. An evidence-based approach to cleft palate repair. Plast Reconstr Surg 2010; 126: 2216-21.
2. Takemura H, Yasumoto K, Toi T, Hosoyamada A. Correlation of cleft type with incidence of perioperative respiratory complications in infants with cleft lip and palate. Paediatr Anaesth 2002; 12: 585-8.

3. Chiono J, Raux O, Bringuier S, Sola C, Bigorre M, Capdevila $\mathrm{X}$, et al. Bilateral suprazygomatic maxillary nerve block for cleft palate repair in children: a prospective, randomized, double-blind study versus placebo. Anesthesiology 2014; 120 : 1362-9.

4. Bosenberg A. Benefits of regional anesthesia in children. Paediatr Anaesth 2012; 22: 10-8.

5. Morton NS, Errera A. APA national audit of pediatric opioid infusions. Paediatr Anaesth 2010; 20: 119-25.

6. Singh B, Srivastava SK, Dang R. Anatomic considerations in relation to the maxillary nerve block. Reg Anesth Pain Med 2001; 26: 507-11.

7. Captier G, Dadure C, Leboucq N, Sagintaah M, Canaud N. Anatomic study using three-dimensional computed tomographic scan measurement for truncal maxillary nerve blocks via the suprazygomatic route in infants. J Craniofac Surg 2009; 20: 224-8.

8. Mesnil M, Dadure C, Captier G, Raux O, Rochette A, Canaud $\mathrm{N}$, et al. A new approach for peri-operative analgesia of cleft palate repair in infants: the bilateral suprazygomatic maxillary nerve block. Paediatr Anaesth 2010; 20: 343-9.

9. Prigge L, van Schoor AN, Bosman MC, Bosenberg AT. Clinical anatomy of the maxillary nerve block in pediatric patients. Paediatr Anaesth 2014; 24: 1120-6.

10. Lee MJ, Koo DJ, Choi YS, Lee KC, Kim HY. Dexamethasone or dexmedetomidine as local anesthetic adjuvants for ultrasound-guided axillary brachial plexus blocks with nerve stimulation. Korean J Pain 2016; 29: 29-33.

11. Marhofer P, Harrop-Griffiths W, Kettner SC, Kirchmair L. Fifteen years of ultrasound guidance in regional anaesthesia: part 1. Br J Anaesth 2010; 104: 538-46.

12. Faul F, Erdfelder E, Lang AG, Buchner A. G*Power 3: a flexible statistical power analysis program for the social, behavioral, and biomedical sciences. Behav Res Methods 2007; 39: 17591.

13. Splinter WM, Semelhago LC, Chou S. The reliability and validity of a modified CHEOPS pain score. Anesth Analg 1994; 78: S413.

14. Culebras X, Van Gessel E, Hoffmeyer P, Gamulin Z. Clonidine combined with a long acting local anesthetic does not prolong postoperative analgesia after brachial plexus block but does induce hemodynamic changes. Anesth Analg 2001; 92: 199-204.

15. Jamieson S. Likert scales: how to (ab)use them. Med Educ 2004; 38: 1217-8.

16. Kulkarni KR, Patil MR, Shirke AM, Jadhav SB. Perioperative respiratory complications in cleft lip and palate repairs: an audit of 1000 cases under 'Smile Train Project'. Indian J An- 
aesth 2013; 57: 562-8.

17. Law RC, de Klerk C. Anaesthesia for cleft lip and palate surgery. Updates in Anesthesia 2002; 14: 27-30.

18. Desalu I, Adeyemo W, Akintimoye M, Adepoju A. Airway and respiratory complications in children undergoing cleft lip and palate repair. Ghana Med J 2010; 44: 16-20.

19. Reena, Bandyopadhyay KH, Paul A. Postoperative analgesia for cleft lip and palate repair in children. J Anaesthesiol Clin Pharmacol 2016; 32: 5-11.

20. Abdallah FW, Brull R. Facilitatory effects of perineural dexmedetomidine on neuraxial and peripheral nerve block: a systematic review and meta-analysis. Br J Anaesth 2013; 110: 915-25.

21. Bhana N, Goa KL, McClellan KJ. Dexmedetomidine. Drugs 2000; 59: 263-8.

22. Almarakbi WA, Kaki AM. Addition of dexmedetomidine to bupivacaine in transversus abdominis plane block potentiates post-operative pain relief among abdominal hysterectomy patients: a prospective randomized controlled trial. Saudi J Anaesth 2014; 8: 161-6.

23. Vorobeichik L, Brull R, Abdallah FW. Evidence basis for using perineural dexmedetomidine to enhance the quality of brachial plexus nerve blocks: a systematic review and metaanalysis of randomized controlled trials. Br J Anaesth 2017; 118: 167-81.

24. Song JH, Shim HY, Lee TJ, Jung JK, Cha YD, Lee DI, et al. Comparison of dexmedetomidine and epinephrine as an adjuvant to $1 \%$ mepivacaine in brachial plexus block. Korean J Anesthesiol 2014; 66: 283-9.

25. Jonnavithula N, Durga P, Madduri V, Ramachandran G, Nuvvula R, Srikanth R, et al. Efficacy of palatal block for analgesia following palatoplasty in children with cleft palate. Paediatr Anaesth 2010; 20: 727-33.

26. Sola C, Raux O, Savath L, Macq C, Capdevila X, Dadure C. Ultrasound guidance characteristics and efficiency of suprazygomatic maxillary nerve blocks in infants: a descriptive prospective study. Paediatr Anaesth 2012; 22: 841-6.

27. Kamath MR, Mehandale SG, Us R. Comparative study of greater palatine nerve block and intravenous pethidine for postoperative analgesia in children undergoing palatoplasty. Indian J Anaesth 2009; 53: 654-61.

28. Obayah GM, Refaie A, Aboushanab O, Ibraheem N, Abdelazees M. Addition of dexmedetomidine to bupivacaine for greater palatine nerve block prolongs postoperative analgesia after cleft palate repair. Eur J Anaesthesiol 2010; 27: 280-4.

29. Mostafa MF, Herdan R, Elshazly M. Comparative study of levobupivacaine and bupivacaine for bilateral maxillary nerve block during pediatric primary cleft palate surgery: a randomized double-blind controlled study. Korean J Anesthesiol 2018; 71: 135-40.

30. Ahmed SA, Elmawy MG, Magdy AA. Effect of the use of dexmedetomidine as an adjuvant in peribulbar anesthesia in patients presented for vitreoretinal surgeries. Egypt J Anaesth 2018; 34: 27-32.

31. Anand VG, Kannan M, Thavamani A, Bridgit MJ. Effects of dexmedetomidine added to caudal ropivacaine in paediatric lower abdominal surgeries. Indian J Anaesth 2011; 55: 340-6.

32. Wu HH, Wang HT, Jin JJ, Cui GB, Zhou KC, Chen Y, et al. Does dexmedetomidine as a neuraxial adjuvant facilitate better anesthesia and analgesia? A systematic review and metaanalysis. PLoS One 2014; 9: e93114.

33. Fritsch G, Danninger T, Allerberger K, Tsodikov A, Felder TK, Kapeller M, et al. Dexmedetomidine added to ropivacaine extends the duration of interscalene brachial plexus blocks for elective shoulder surgery when compared with ropivacaine alone: a single-center, prospective, triple-blind, randomized controlled trial. Reg Anesth Pain Med 2014; 39: 3747.

34. Kim KH. Safe sedation and hypnosis using dexmedetomidine for minimally invasive spine surgery in a prone position. Korean J Pain 2014; 27: 313-20. 